\title{
Association genetics in Solanum tuberosum provides new insights into potato tuber bruising and enzymatic tissue discoloration
}

Claude Urbany ${ }^{1 *}$, Benjamin Stich ${ }^{1}$, Lysann Schmidt ${ }^{1}$, Ludwig Simon², Hergen Berding ${ }^{3}$, Holger Junghans ${ }^{4}$, Karl-Heinz Niehoff ${ }^{5}$, Alexander Braun ${ }^{6}$, Eckhard Tacke ${ }^{7}$, Hans-Rheinhardt Hofferbert $^{8}$, Jens Lübeck ${ }^{9}$, Josef Strahwald ${ }^{9}$ , Christiane Gebhardt ${ }^{1}$

\begin{abstract}
Background: Most agronomic plant traits result from complex molecular networks involving multiple genes and from environmental factors. One such trait is the enzymatic discoloration of fruit and tuber tissues initiated by mechanical impact (bruising). Tuber susceptibility to bruising is a complex trait of the cultivated potato (Solanum tuberosum) that is crucial for crop quality. As phenotypic evaluation of bruising is cumbersome, the application of diagnostic molecular markers would empower the selection of low bruising potato varieties. The genetic factors and molecular networks underlying enzymatic tissue discoloration are sparsely known. Hitherto there is no association study dealing with tuber bruising and diagnostic markers for enzymatic discoloration are rare.

Results: The natural genetic diversity for bruising susceptibility was evaluated in elite middle European potato germplasm in order to elucidate its molecular basis. Association genetics using a candidate gene approach identified allelic variants in genes that function in tuber bruising and enzymatic browning. Two hundred and five tetraploid potato varieties and breeding clones related by descent were evaluated for two years in six environments for tuber bruising susceptibility, specific gravity, yield, shape and plant maturity. Correlations were found between different traits. In total 362 polymorphic DNA fragments, derived from 33 candidate genes and 29 SSR loci, were scored in the population and tested for association with the traits using a mixed model approach, which takes into account population structure and kinship. Twenty one highly significant $(p<0.001)$ and robust marker-trait associations were identified.
\end{abstract}

Conclusions: The observed trait correlations and associated marker fragments provide new insight in the molecular basis of bruising susceptibility and its natural variation. The markers diagnostic for increased or decreased bruising susceptibility will facilitate the combination of superior alleles in breeding programs. In addition, this study presents novel candidates that might control enzymatic tissue discoloration and tuber bruising. Their validation and characterization will increase the knowledge about the underlying biological processes.

\section{Background}

Enzymatic browning is a phenomenon frequently observed in fruits and vegetables upon physical damage. The tissue discoloration results from the oxidation of endogenous phenolic compounds, which is catalyzed by oxidoreductases, notably polyphenol oxidases (PPOs) or tyrosinases in the presence of oxygen [1-8]. Besides the

\footnotetext{
* Correspondence: urbany@mpipz.mpg.de

${ }^{1}$ Max Planck Institute for Plant Breeding Research, 50829 Cologne; Germany Full list of author information is available at the end of the article
}

unappealing tissue pigmentation, enzymatic browning affects nutritional properties, flavour and texture of food and feed during storage or processing and is therefore detrimental to food quality. Mechanical impact during harvest, transport and storage of potato tubers initiates the development of an internal tissue discoloration ('blackspot bruising'). Blackspot bruising leads to the rejection of the crop by consumers, the retail and the processing industry, which results in considerable economic losses. 'After cooking darkening' is another problematic consequence of enzymatic browning.

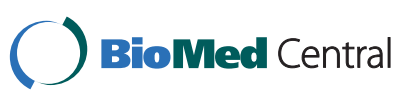

(c) 2011 Urbany et al; licensee BioMed Central Ltd. This is an Open Access article distributed under the terms of the Creative Commons Attribution License (http://creativecommons.org/licenses/by/2.0), which permits unrestricted use, distribution, and reproduction in any medium, provided the original work is properly cited. 


\section{Environment}

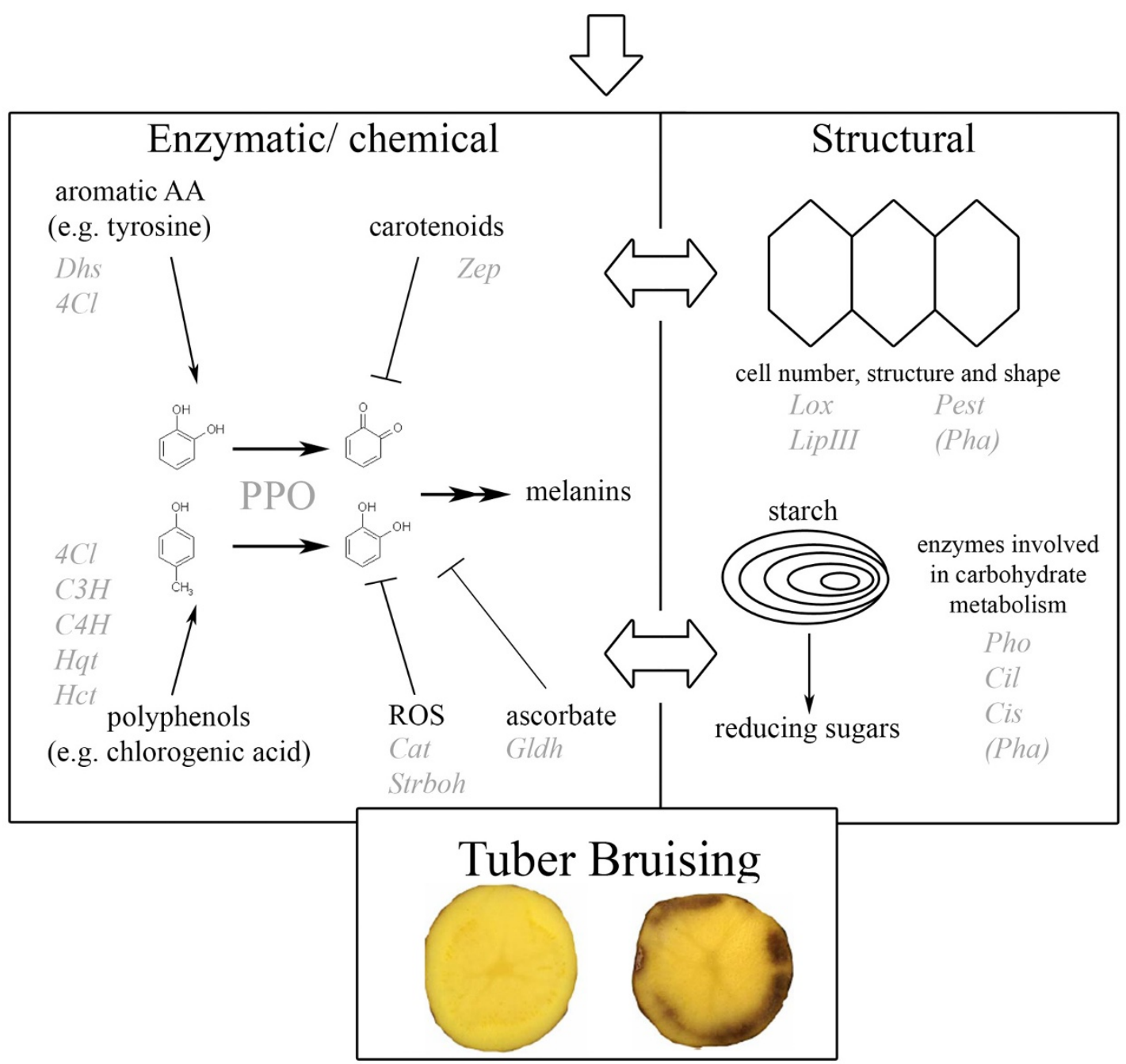

Figure 1 Simplified metabolic scheme of potato tuber bruising and the candidate genes used in the association experiment. Shown are the enzymatic/chemical, structural and environmental components and the involved genes with their corresponding abbreviations. The abbreviations are: $\mathrm{AA}=\mathrm{Amino}$ acid; $\mathrm{ROS}=$ reactive oxygen species $\mathrm{PPO}=$ Polyphenoloxidase, $4 \mathrm{Cl}=4$-coumarate:CoA ligase, $\mathrm{C} 3 \mathrm{H}=\mathrm{p}$-coumarate 3-hydroxylase, $\mathrm{C} 4 \mathrm{H}=$ Cinnamic acid 4-hydroxylase; Cil = ATP citrate lyase, Cis = Mitochondrial citrate synthase, Cat = Catalase, Dhs = 3-deoxy-7phosphoheptulonate synthase, Gldh = L-galactono-1,4-lactone dehydrogenase, Hct = Hydroxycinnamoyl transferase, Hqt = Hydroxycinnamoyl CoA quinate transferase, LipIII = Triacylglycerol lipase III, Lox = Lipoxygenase, Pest = pectin methyl esterase, Pha = plasma memebrane ATPase; proton pump, Pho $=\alpha$-glucan phosphorylase L-type, Strboh $=$ Solanum tuberosum respiratory burst oxidase homologue, Zep $=$ zeaxanthin epoxidase.

When cells are damaged, phenolic compounds present in the vacuoles are oxidized to quinones by PPOs located in the plastids (chloroplasts and amyloplasts). The quinones polymerize non-enzymatically further into dark pigments (melanins), attributing a dark gray to black appearance to the normally white to yellowish tissue $[9,10]$ (Figure 1). Bruising symptoms emerge 3 to 24 hours after the impact and the damaged tissue area is only seen after removal of the tuber skin. Previous studies report that the discoloration reaction strongly depends on PPO enzyme activity [11-14]. Potato PPOs are encoded by a small gene family of at least six members, namely POTP1 and POTP2 [15], POT32, POT33, POT41, and POT72 [16], which show tissue specific expression. In contrast to POTP1 and POTP2, which are mainly expressed in leaves and flowers [16], POT32 is 
considered to be the major form expressed in tubers besides POT33 and POT72. Silencing PPO gene expression resulted in transgenic potato lines that exhibited a significantly reduced discoloration reaction [17-19]. This observation further points to the important role of $\mathrm{PPO}$ enzyme activity for bruising. In addition, it has been shown that molecular markers derived from the POT32 sequence co-localise with a quantitative trait locus (QTL) for enzymatic discoloration on potato chromosome VIII in a diploid potato mapping population [20]. Taken together, functional and genetic studies suggest PPOs as major candidate genes for influencing tissue discoloration and tuber bruising. The role of the cellular levels of the PPO substrates is less clear. Contrasting findings do not allow a clear statement on the impact on discoloration and tuber bruising of chlorogenic acid contents, the main phenolic compound in potato tubers, of its precursor tyrosine and the partitioning of tyrosine between tuber protein and the free amino acid pool $[10,21,22]$. In addition to PPO and its substrates, reducing agents such as ascorbate and carotenoids as well as redox homeostasis influence tuber bruising [23,24]; Figure 1. Besides the enzymatic component, structural factors like cellular membrane stability, cell number and architecture also affect tuber bruising [9,25] (Figure 1). The latter characters not only influence tuber bruising but are also involved in other tuber traits like tuber shape, starch and sugar content of tubers, and tuber yield [26,27]. Starch accounts for $10-25 \%$ of the tuber fresh weight and is the major storage compound of potato tubers [28]. The amount and steric properties of starch granules influence tuber starch content, which correlates with specific gravity [29] and thereby affect cellular stability and tuber bruising.

The susceptibility of potato tubers to blackspot bruising is a complex trait, which depends on multiple genetic factors, developmental stage and environment [9]. Potato breeding programs aim at the selection of cultivars with improved genetic resistance to bruising as an important quality trait. However, the phenotypic evaluation of bruising susceptibility is difficult. It requires large amounts of tubers, which become only available after several years of vegetative multiplication. Multiyear and -location trials are needed to separate genetic variability from the environmental one. This prevents the selection of low bruising cultivars early in the breeding cycle. An additional problem is the correlation between blackspot bruising and specific gravity, which makes the selection of superior alleles for resistance to blackspot bruising independent from specific gravity difficult. Identifying the molecular basis of the genetic variation of bruising susceptibility will therefore facilitate the early selection of low bruising cultivars by means of molecular markers. Such markers can be used to diagnose and select for or against superior or inferior alleles of the genes themselves that control bruising in parents and progeny of breeding programs. Besides application in breeding, knowledge of which and how gene variants influence the bruising phenotype will contribute to understanding the complex molecular and cellular networks involved in enzymatic browning in plants.

The identification of quantitative trait loci (QTL) underlying complex phenotypic traits became feasible with the introduction of DNA-based markers [30]. Since then, a number of genes and their allelic variants underlying plant QTL have been identified by positional cloning [reviewed in [31]]. Positional QTL cloning is a laborious and time-intensive process, which is feasible in inbreeding species such as Arabidopsis and rice but is severely handicapped in polyploid, non-inbred species such as potato [32]. Moreover, the bruising phenotype itself is rather prohibitive for positional cloning due to the difficulties of the phenotypic evaluation as outlined above. An alternative to positional QTL cloning is the candidate gene approach, which is based on the knowledge of a gene's function in controlling a character of interest on the one hand, and genetic co-localization of a functional candidate gene with QTL for the character of interest on the other [33]. The investigation of DNA variation at loci fulfilling these criteria in natural populations of individuals related by descent [34] can lead to the detection of associations with positive or negative character values [35-38]. Finding such associations indicates that DNA variation, either at the candidate locus itself or at a linked locus is causal for the phenotypic variation. The extent of linkage disequilibrium (LD) present in the population under study determines the amount of indirect associations due to physical linkage. Validation of a direct association between a candidate gene allele and a QTL effect can be achieved by quantitative complementation analysis [38]. Whether the association is direct or indirect, association mapping can produce diagnostic markers for superior alleles of genes influencing phenotypic variation, thereby empowering plant breeding.

To dissect the molecular basis of tuber bruising susceptibility and to identify diagnostic markers for "precision breeding", we conducted an association mapping study in a population of tetraploid genotypes used for potato variety development. In addition to bruising, the population was phenotyped for specific gravity, yield, tuber shape and plant maturity, in order to determine the correlation of these traits with bruising susceptibility. We genotyped the population with a series of DNAbased markers developed from candidate gene sequences. Candidate genes (Figure 1) were selected from the scientific literature and de novo from comparative proteomics of bruising resistant versus bruising 
susceptible cultivars (Urbany et al., in preparation). Highly significant marker-trait associations were detected for bruising susceptibility and other traits, which are discussed with respect to the mechanisms underlying natural variation of enzymatic discoloration and tuber bruising.

\section{Results}

\section{Phenotypic analysis}

Balanced phenotypic data from two years were obtained for 205 genotypes ( 85 varieties evaluated at six locations, and $6 \times 20$ breeding clones evaluated at one location each, (Additional file 1), except for yield (NE and SA data sets missing) and maturity (NE data set missing). The phenotypic and genotypic data of the six data sets EU, SA, NO, BS, NE and BE, corresponding to location and breeder, were combined and constituted the data set ALL, which was used for the association analysis. Heritability $\left(H^{2}\right)$ was high for all traits except yield. Apart from the NE data set, bruising index (BI) as well as starch corrected bruising (SCB) showed a high overall heritability. Specific gravity (SG) was characterized by high $H^{2}$ values in every single data set. Low $H^{2}$ values were identified for tuber shape (TS) and plant maturity (PM) in the NO data set and in all single data sets concerning tuber yield (TY) (Table 1). The phenotypic distributions (adjusted entry means) of BI, SG, SCB, TY TS and PM in the ALL population are given in Figure 2. The ALL population showed a trend to BI below 30 points and SG between 12 and 16 percent (Figure 2A, $B)$. In addition, genotypes were characterized by a mid plant maturity of about four or lower on the scale ranging from zero to nine (Figure. 2E). Correlation analyses of the phenotypic data pinpointed to a highly significant, positive correlation between BI and SG (Figure 3A). Accordingly, the majority of the genotypes highly susceptible to bruising had a specific gravity of $15 \%$ and more (Figure 3A). SCB did not correlate with SG, and

\begin{tabular}{|c|c|c|c|c|c|c|}
\hline Data set & BI & SG & SCB & TY & PM & TS \\
\hline BS & 0.874 & 0.931 & 0.684 & 0.540 & 0.738 & 0.841 \\
\hline NO & 0.904 & 0.902 & 0.905 & 0.622 & 0.590 & 0.499 \\
\hline EU & 0.928 & 0.971 & 0.880 & 0.641 & 0.845 & 0.817 \\
\hline BE & 0.783 & 0.957 & 0.632 & 0.262 & 0.999 & 0.640 \\
\hline SA & 0.914 & 0.966 & 0.812 & NA & 0.938 & 0.928 \\
\hline NE & 0.488 & 0.804 & 0.406 & NA & NA & 0.798 \\
\hline ALL & 0.864 & 0.925 & 0.772 & 0.375 & 0.831 & 0.819 \\
\hline
\end{tabular}

$\mathrm{NA}=$ Not available; $\mathrm{BS}=$ Bavaria Saat; NO = Norika; EU = Europlant; $\mathrm{BE}=$ Berding; $\mathrm{SA}=$ Saka; $\mathrm{NE}=$ Niehoff; $\mathrm{ALL}=$ combined data set.

Values were obtained using collected data in a population of 205 tetraploid potato genotypes in a two year trial at multiple environments. genotypes with positive SCB scores, indicating bruising susceptibility, were distributed evenly over all SG classes (Figure 3B). Significant correlations were also observed between some other traits (Table 2). SCB clearly correlated positively with BI and negatively with TS. Genotypes highly susceptible to bruising were characterized by elevated SCB values and a trend of circular to ovoid tuber shape that also correlated with increasing SG. PM correlated slightly but significantly with BI as well as with SG. Later maturing genotypes showed on average a higher specific gravity and elevated bruising susceptibility. A very weak positive correlation between yield and tuber shape and a negative one between yield and SG were also identified.

\section{Association analysis}

First, population structure was analysed by principal coordinate analysis using the genotypic data of 157 SSR alleles scored at 29 loci (between 1 and 9 alleles per locus) distributed on all twelve potato chromosomes. No distinct subgroups were observed (Figure 4). A total of 362 polymorphic DNA fragments derived from 33 candidate genes and 29 SSR loci were scored in the 205 individuals (Additional file 2 and 3). DNA polymorphisms were tested individually for association with all traits using a mixed model approach, which takes into account population structure and kinship, as well as by stepwise forward regression. Twenty one and eighty six marker-trait associations were found that were significant at $\mathrm{P}<0.001$ (Table 3; for exemplary separation panes see Additional file 4) and $\mathrm{P}<0.01$ (Additional file 2 ), respectively. At $\mathrm{P}<0.001,13$ polymorphic fragments that originated from five candidate and two SSR loci were associated with tuber bruising (BI and/or SCB (Table 3)). Interestingly, markers derived from PPO isoforms influenced tuber bruising in opposite directions, either decreasing or increasing bruising susceptibility compared to the population mean. For example, the SSCP marker POT32PS1- $f$ with a frequency of only ten percent in the ALL population, decreased BI and SCB by 14.4 and 12.4 points, respectively. In contrast, the POLOXA marker with a frequency of 35 percent increased BI and SCB by 11.2 and 7.8 points, respectively (Additional file. 2). Markers from the starch phosphorylase PHO1A were all associated with increased bruising susceptibility, whereas markers from lipase class III, 4-coumarate CoA ligase and HQT on average lowered bruising (Table 3). In addition, the SSR alleles StIO24-e and StIO13-a showed association with BI and SG but not with SCB. In contrast to the highly frequent StI024-e allele (90\% presence in the population), which decreased bruising susceptibility and specific gravity (Table 3), the StI013- $a$ allele increased trait values when compared to population mean scores. 


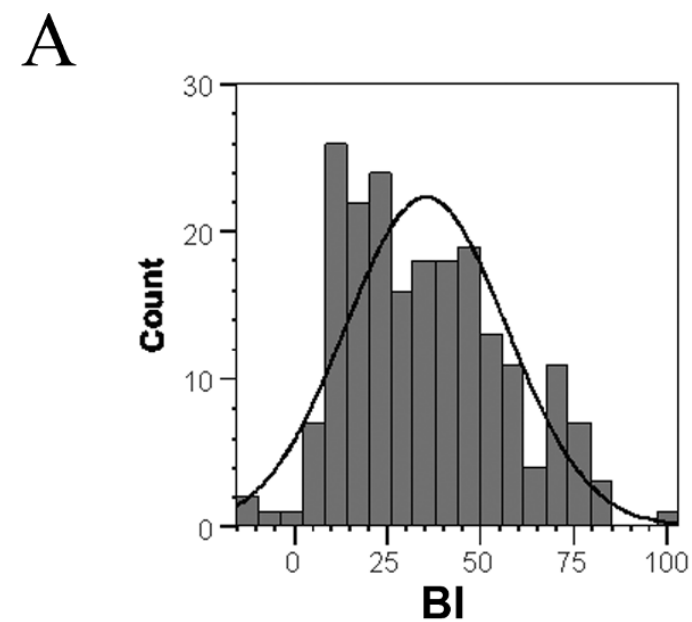

$\mathrm{C}$

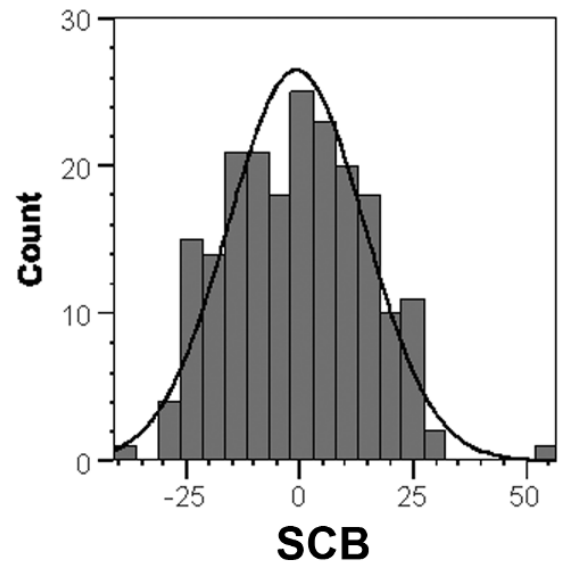

$\mathrm{E}$

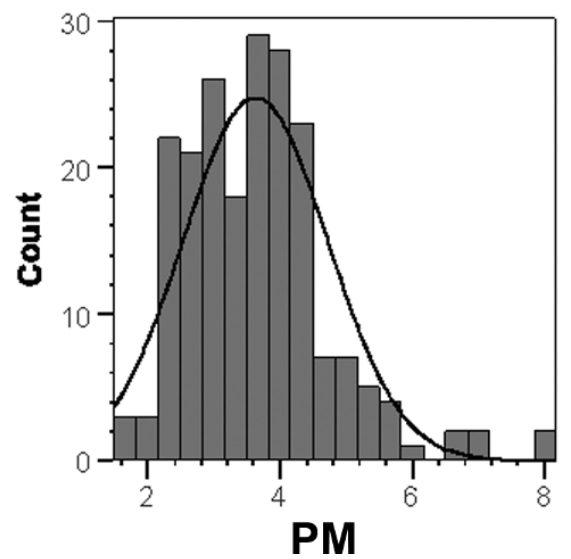

B

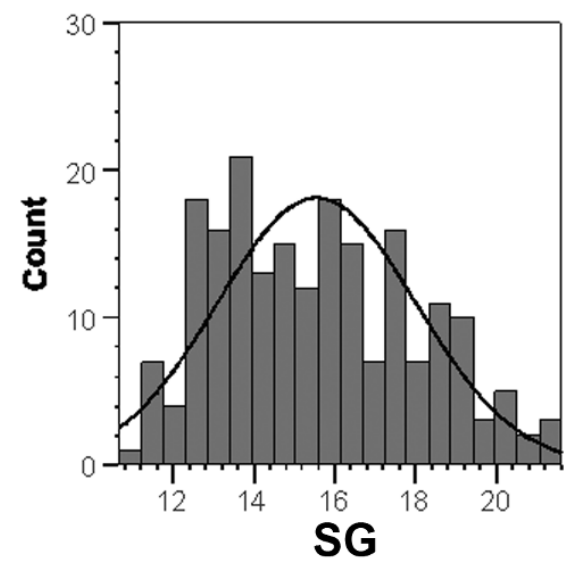

$\mathrm{D}$

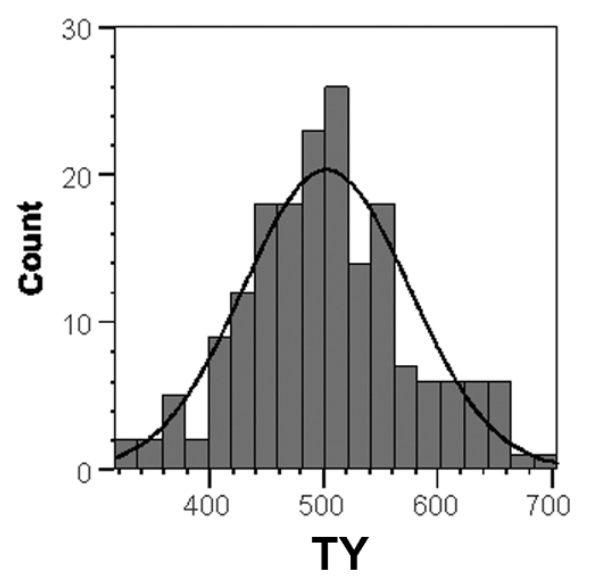

F

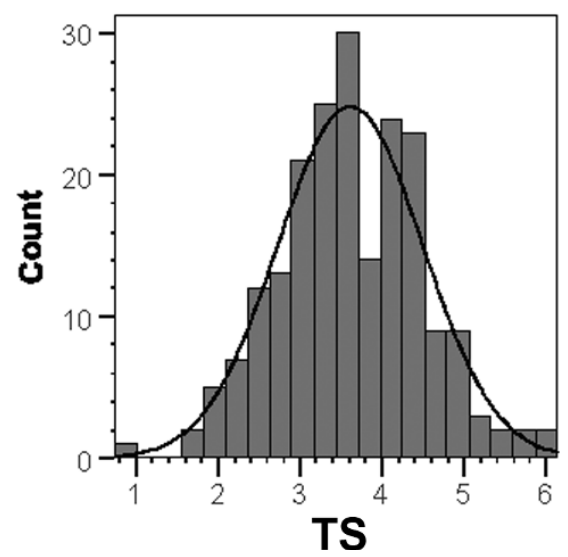

Figure 2 Phenotypic distribution of adjusted means of tuber quality traits. The histograms display the number of genotypes (counts) that are present in a specific phenotypic class for the given trait. (A) Bruising index (BI) from 0 to 100 was calculated as described in materials and methods. (B) Specific gravity (SG) is displayed as percent fresh weight. (C) The values for starch corrected bruising (SCB) were derived from BI and SG as described in materials and methods (D) Tuber yield (TY) is shown as decitons per hectar. (E) Plant maturity (PM) and (F) tuber shape (TS) are given as scores between 1 (very early, circular tuber shape) and 9 (very late, oblong tuber shape). Histograms and the normal distribution curve were generated using SPSS software (SPSS Inc; Chicago, Illinois 60606 USA). 


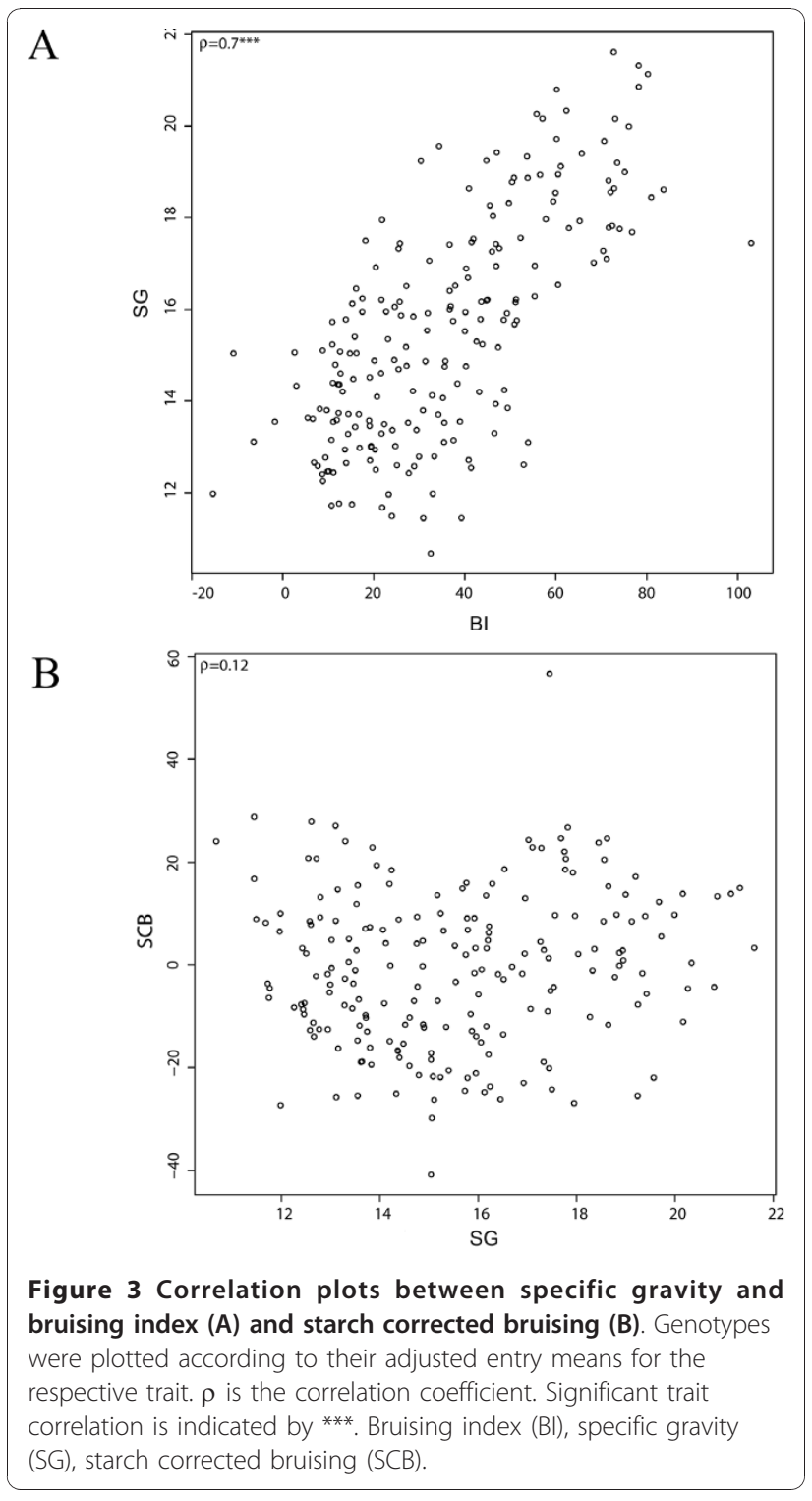

The candidate gene markers that showed highly significant association with SG were all derived from the starch phosphorylase genes $P H O 1 A$ and $P H O 1 B$ (alternative names $S t p 23$ and $S t p L$, respectively [35]). The PHO1A- $b$ fragment increased, whereas the $P H O 1 B-1 a$

Table 2 Correlation matrix of bruising index (BI), specific gravity (SG), starch corrected bruising (SCB), tuber yield (TY), plant maturity (PM) and tuber shape (TS)

\begin{tabular}{lccccc}
\hline & BI & SG & SCB & TY & PM \\
\hline SG & $0.7^{* * *}$ & & & & \\
SCB & $0.78^{* * *}$ & ns & & & \\
TY & ns & $-0.18^{*}$ & ns & & \\
PM & $0.35^{* * *}$ & $0.46^{* * *}$ & ns & $0.25^{* * *}$ & \\
TS & $-0.47^{* * *}$ & $-0.44^{* * *}$ & $-0.28^{* * *}$ & $0.17^{*}$ & ns \\
\hline
\end{tabular}

* significant at $\alpha=0.05$; ${ }^{* *}$ significant at $\alpha=0.001, \mathrm{~ns}=$ not significant

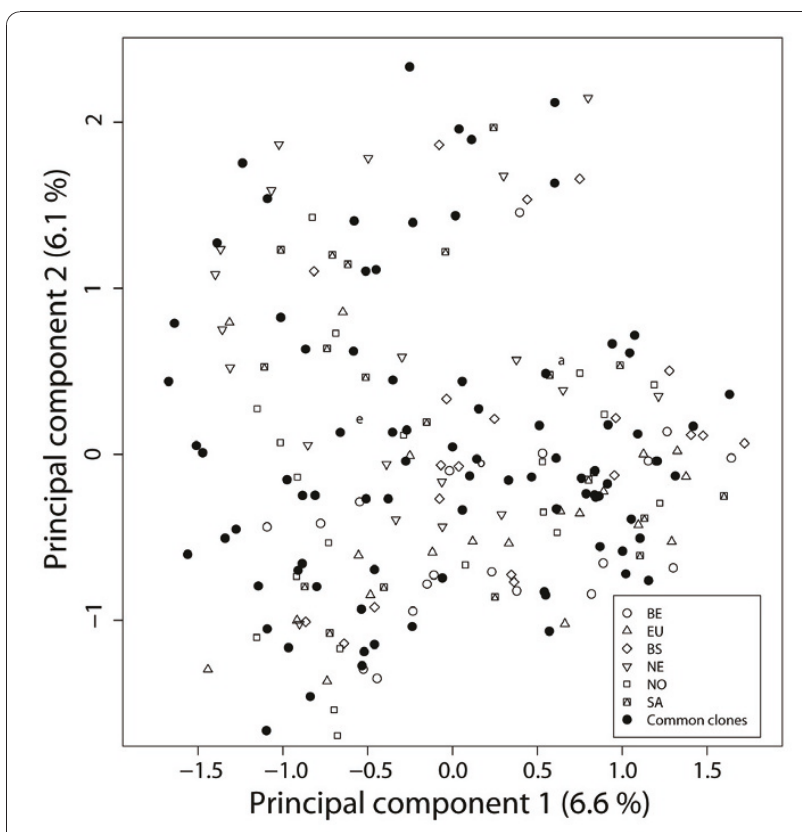

Figure 4 Principal coordinate analysis of 205 tetraploid potato genotypes. Principal coordinate analysis was performed using the SSR genotyping data. The common varieties are represented with black dots. Breeding clones are referred to by the corresponding breeder abreviation. Berding (BE), Europlant (EU), Bavaria Saat (BS), Niehoff (NE), Norika (NO), SaKa (SA) and the corresponding symbol.

and $P H O 1 B-1 b$ fragments decreased specific gravity. In general, markers that were associated with both BI and SG showed a concerted allele effect, either increasing or decreasing bruising susceptibility and specific gravity (Table 3 and 4, Additional file 2). This corresponds to the phenotypic correlation observed between these traits. All $P H O 1 B$ markers associated with both $\mathrm{BI}$ and SG did not show association with SCB. Markers specifically associated with tuber bruising (BI and/or SCB), independent from specific gravity, originated from the candidate genes PPO (POLOXA, POT32PS1-f), lipase class III (LIPIII-27-1h), hydroxycinnamoyl CoA quinate transferase $(H Q T-c)$, starch phosphorylase L-type (PHO1A-a) and the SSR locus M2O (M2O-b) (Table 3 and 4, Additional file 2). The SSR locus M2O is located in a cluster of protease inhibitor genes on potato chromosome III [39]. Compared with the traits BI and SG, a lower number of markers were associated with tuber yield, shape and plant maturity. For TS and PM, no markers associated at $\mathrm{P}<0.001$ were identified. The markers associated at $\mathrm{P}<0.01$ are included in Additional file 2. Seven markers that were associated with $\mathrm{BI}$, SG and/or SCB were also associated with TS (Table 4). In all cases, the direction of the effect on TS was opposite to the effect on BI, SG and SCB, in concordance with the correlation of round tuber shape with increased bruising susceptibility and specific gravity. Two unique 
Table 3 Marker trait associations in the ALL population $(P<0.001)$

\begin{tabular}{|c|c|c|c|c|c|c|c|}
\hline Trait $^{1}$ & Gene & Metabolism & Marker allele & Chromosome & Allele Effect & $\mathrm{p}$ value & Fr. $(\%)^{2}$ \\
\hline \multirow[t]{9}{*}{$\mathrm{BI}$} & Starch phosphorylase L-type & Starch & PHO1A-b & III & $4 \uparrow 17.8 \pm 4$ & $1.41 \cdot 10^{-5}$ & 12.4 \\
\hline & & & PHOIA-C & III & $\uparrow 13.3 \pm 3.3$ & $6.3 \cdot 10^{-5}$ & 20.8 \\
\hline & & & PHO1A-a & III & $\uparrow 20.6 \pm 6$ & 0.00070 & 7.1 \\
\hline & Lipase class III & Lipids & LIPIII-27-1h & $\|$ & $\downarrow 15.8 \pm 3.8$ & $4.6 \cdot 10^{-5}$ & 80.4 \\
\hline & PPO isoform potpoloxA & Polyphenols & POLOXA & VIII & $\uparrow 11.2 \pm 3.1$ & 0.00033 & 35.5 \\
\hline & 4-coumarate CoA Ligase & Phenylpropanoids & $4 C L-16$ & III & $\downarrow 10.6 \pm 2.7$ & 0.00016 & 59.1 \\
\hline & & & $4 C L-2 C$ & III & $\downarrow 9.5 \pm 2.8$ & 0.00091 & 49.3 \\
\hline & non coding SSR & - & Stlo24-e & $\|$ & $\downarrow 17.9 \pm 5.1$ & 0.00051 & 90.2 \\
\hline & non coding SSR & - & Stlo13-a & III & $\uparrow 11.1 \pm 3.2$ & 0.00058 & 44.4 \\
\hline \multirow[t]{6}{*}{ SG } & Starch phosphorylase L-type & Starch & PHO1B-16 & V & $\downarrow 1.35 \pm 0.37$ & 0.00036 & 30.6 \\
\hline & & & PHO1B-1a & V & $\downarrow 1.20 \pm 0.34$ & 0.00051 & 63.1 \\
\hline & Starch phosphorylase L-type & Starch & PHO1A-b & III & $\uparrow 1.60 \pm 0.46$ & 0.00070 & 12.4 \\
\hline & non coding SSR & - & StI024-e & $\|$ & $\downarrow 2.06 \pm 0.58$ & 0.00047 & 90.2 \\
\hline & non coding SSR & - & Stl013-a & III & $\uparrow 1.36 \pm 0.36$ & 0.00023 & 44.4 \\
\hline & non coding SSR & - & SSR327-a & VIII & $\uparrow 1.80 \pm 0.48$ & 0.00026 & 17.7 \\
\hline \multirow[t]{4}{*}{$\mathrm{SCB}$} & Lipase class III & Lipids & LIPIII-27-1h & $\|$ & $\downarrow 10.3 \pm 2.8$ & 0.00028 & 80.4 \\
\hline & Hydroxycinnamoyl quinate CoA transferase & Polyphenols & $H Q T-C$ & VII & $\downarrow 13.0 \pm 3.3$ & 0.00023 & 45.9 \\
\hline & $\mathrm{PPO}$ isoform pot32 & Polyphenols & POT32PS1-Hpy-f & VIII & $\downarrow 12.4 \pm 3.4$ & 0.00039 & 10.2 \\
\hline & PPO isoform potpoloxA & Polyphenols & POLOXA & VIII & $\uparrow 7.8 \pm 2.3$ & 0.00064 & 35.5 \\
\hline \multirow[t]{2}{*}{ TY } & L-galactono-1,4-lactone dehydrogenase & Ascorbate synthesis & GLDH-h & -3 & $\downarrow 55.7 \pm 14.2$ & 0.00012 & 81.3 \\
\hline & Hydroxycinnamoyl quinate CoA transferase & Polyphenols & HQT-f & $\mathrm{VII}$ & $\uparrow 35.9 \pm 10.6$ & 0.00084 & 54.7 \\
\hline
\end{tabular}

${ }^{1}$ BI: bruising index; SG: specific gravity; SCB: starch corrected bruising; TY: tuber yield.

${ }^{2}$ Frequency of presence of the marker fragment in the ALL population.

${ }^{3}$ Map position not known.

${ }^{4}$ Direction of effect either positive $(\uparrow)$ or negative $(\downarrow)$.

Table 4 Multiple trait associations of significant marker alleles $(P<0.01)$

\begin{tabular}{|c|c|c|c|c|c|c|}
\hline Marker allele & $\mathrm{BI}$ & SG & SCB & TS & PM & TY \\
\hline PHOIA-b & $\uparrow^{1}$ & $\uparrow$ & $\uparrow$ & & & \\
\hline PHOIA-C & $\uparrow$ & $\uparrow$ & $\uparrow$ & $\downarrow$ & & \\
\hline PHO1A-a & $\uparrow$ & & $\uparrow$ & & & \\
\hline PHO1B-16 & $\downarrow$ & $\downarrow$ & & $\uparrow$ & & \\
\hline PHOIB-1f & $\uparrow$ & $\uparrow$ & & & & \\
\hline LIPIII-27-1e & $\uparrow$ & $\uparrow$ & & & & \\
\hline LIPIII-27-1h & $\downarrow$ & & $\downarrow$ & $\uparrow$ & & \\
\hline LIPIII-27-a & & $\uparrow$ & & & & $\downarrow$ \\
\hline POLOXA & $\uparrow$ & & $\uparrow$ & & & \\
\hline POLOXB & $\downarrow$ & $\downarrow$ & & & & \\
\hline POT32PS1-Hpy-f & $\downarrow$ & & $\downarrow$ & & & \\
\hline$M 20-b$ & $\downarrow$ & & $\downarrow$ & & & \\
\hline $4 \mathrm{Cl}-1 \mathrm{~b}$ & $\downarrow$ & $\downarrow$ & & & & \\
\hline $4 \mathrm{Cl}-2 \mathrm{C}$ & $\downarrow$ & $\downarrow$ & & & $\downarrow$ & \\
\hline Stlo24-e & $\downarrow$ & $\downarrow$ & & $\uparrow$ & & \\
\hline Stlo13-a & $\uparrow$ & $\uparrow$ & & $\downarrow$ & $\uparrow$ & \\
\hline STM1043-b & $\downarrow$ & $\downarrow$ & & & & \\
\hline PHAla-a & $\uparrow$ & & & $\downarrow$ & & \\
\hline CAT2-1C & $\downarrow$ & & & & $\downarrow$ & \\
\hline $\mathrm{C} 3 \mathrm{H}-\mathrm{f}$ & & $\downarrow$ & & $\uparrow$ & & \\
\hline
\end{tabular}

${ }^{1}$ Direction of effect, either trait value increasing $(\uparrow)$ or decreasing $(\downarrow)$. and highly significant associations were found for tuber yield.(Table 3). A SSCP fragment originating from L-galactono-1,4-lactone dehydrogenase $(G L D H-h)$ was associated with a decrease in yield of $55.7 \mathrm{dt} / \mathrm{ha}$ compared to the population mean. This marker had a high allele frequency of $81 \%$ in the population (Table 3 ). $H Q T-f$, another SSCP fragment originating from hydroxycinnamoyl quinate CoA transferase, increased tuber yield on average by $35.9 \mathrm{dt} / \mathrm{ha}$. Markers associated with BI, SCB, SG, TS or PM had no effect on tuber yield with the exception of LIPIII-27-a (Table 4). Stepwise linear regression at $\mathrm{P}<0.001$ (Table 5) resulted in the

Table 5 Significant marker fragments identified by stepwise linear regression $(P<\mathbf{0 . 0 0 1})$

\begin{tabular}{lllll}
\hline Trait $^{1}$ & \multicolumn{1}{c}{ BI } & SG & SCB & TY \\
\hline & PHO1A-b & St1013-a & HQT-C & GLDH-h \\
& $4 C L-1 b$ & PHO1B-1a & & \\
Marker Fragment $^{2}$ & St1013-e & PHO1B-1b & & \\
& & & &
\end{tabular}

$\begin{array}{lllll}\text { Exp. Var. }^{3}(\%) & 21,5 & 38,2 & 33,3 & 7,5\end{array}$

${ }^{1}$ Bruising Index (BI), Specific gravity (SG), Starch corrected bruising (SCB), Tuber yield (TY).

${ }^{2}$ Associated marker fragment derived from corresponding candidate gene.

${ }^{3}$ Amount of genetic variance explained by the sum of significant markers at $\mathrm{P}<0.001$. 
identification of three markers associated with $\mathrm{BI}$, which originated from starch phosphorylase Pho1A (PHO1A-b), 4-coumarate CoA Ligase $(4 C L-1 b)$ and the non coding SSR allele StI013-e. The three markers explained together $21.5 \%$ of the genetic variation of this trait. The SSR allele StI013- $a$ in combination with two markers from the Pho1B locus (PHO1B-1a; PHO1B-1b) and the LipIII-27-a marker derived from a putative class III lipase explained $38.2 \%$ of the genetic variation of SG. In the case of SCB, stepwise forward regression resulted in a single significant marker derived from the candidate gene hydroxycinnamoyl quinate CoA transferase $(H Q T-c)$. Concerning yield, the marker fragment $G L D H-h$ was the only one significant at $\mathrm{P}<0.001$. At this significance threshold no markers were identified for the traits tuber shape and plant maturity.

\section{Discussion}

This study aimed at elucidating the genetic basis of blackspot bruising in potato tubers in combination with several other important agronomical traits. The approach was to associate DNA polymorphisms at multiple functional candidate loci with natural phenotypic variation in advanced tetraploid varieties and breeding materials. We identified highly significant $(\mathrm{P}<0.001)$ associations between DNA variants at candidate as well as non-candidate (SSR) loci for tuber bruising, specific gravity and yield. To the best of our knowledge, the association mapping experiment described in this paper is amongst most comprehensive and first that investigates the molecular basis of the natural variation of enzymatic browning in plants. Association genetics in model and non-model plants substantially improved the understanding of the molecular basis of various complex plant phenotypes and their impact on plant performance and economically essential traits [35,40-44]. The human genetics field provides the models how association studies influence the development of novel strategies in medicine [45-48]. In crop genetics, the combination of genomic tools with phenotypic evaluation as used in the traditional breeding process can identify molecular markers useful in "Marker-Assisted Selection" (MAS) and at the same time genetic factors that influence complex traits such as pathogen resistance and crop quality $[35,38,49,50]$.

The experimental design (Additional file. 5) comprised the phenotypic evaluation of tuber bruising, specific gravity, yield and shape as well as plant maturity with standard methods used for variety selection at six different locations in two consecutive years. Similar to a previous association mapping experiment [35], proprietary breeding clones were evaluated at the corresponding singular breeding station, whereas a common set of potato varieties was evaluated at all six breeding stations, which facilitated joint data analysis. This experimental design makes possible to perform studies including proprietary breeding materials that otherwise would not be available, insuring that the associations found are relevant for elite germplasm. Marker-trait associations were detected using a mixed model approach, which took into account field design, environment, genotype by environment interaction, population structure and kinship. An SSR marker based genetic similarity matrix was included in the mixed model to correct for population substructure that was not detectable by principal coordinate analysis. Stepwise forward regression led to a combination of associated markers that collectively explained between 7.5 and 38.2 percent of the genetic variation of the evaluated traits.

The phenotypic data analysis during this study led to several correlations that were observed between the investigated traits. In this respect, the strong positive correlation between bruising susceptibility and specific gravity which is well known in breeding practice was confirmed. In addition, the effects of all markers associated with both traits always had the same direction. A comparable connection between tuber traits exists in the case of specific gravity and chip color, the latter being determined by the amount of reducing sugars in the tubers [35]. One explanation for the correlation between tuber bruising susceptibility and SG is close genetic linkage between different genes that control both traits independently. This might be the case for some QTL but is rather unlikely to be the case for all QTL with concerted effects on both traits that were tagged by the same marker. An alternative explanation concerning the impact of specific gravity upon bruising might be the interaction of starch grains with the surrounding internal membrane ultrastructure. Thus, a high amyloplastic load with starch grains provokes a faster and easier rupture of amyloplastic membranes upon mechanical stress. The loss of membrane integrity results on the one hand in the release of PPO and on the other hand in a mix-up of cytoplasmic and vacuolar compounds leading to the encounter of PPO with phenolic substrates [51-53]. Indeed, associations with tuber bruising and specific gravity were identified with markers derived from PPO genes as well as starch phosphorylase and lipase genes in concordance with this hypothesis. L-type starch phosphorylases (PHO1) are starch degrading enzymes present in plastids. The gene PHO1A (Stp23) on potato chromosome III is expressed in the amyloplasts, whereas PHO1B (StpL) on chromosome $\mathrm{V}$ is expressed mainly in the chloroplasts [54]. The net amount of starch in the plastids is the result of anabolic and katabolic enzymatic reactions, and carbon flux from source leaves to sink tubers. Markers originating from $P H O 1 A$ increased mainly bruising susceptibility 
and to less extent specific gravity. Vice versa, markers derived from $P H O 1 B$ were associated primarily with specific gravity and secondary with bruising. The effects of PHO1A and PHO1B allelic variants on SG verify associations found previously at these two loci in an independent association mapping experiment [35]. The observed concerted allele effects on bruising susceptibility and specific gravity also fit the hypothesis outlined above, which predicts that alleles increasing SG will indirectly increase bruising susceptibility due to a higher load of starch grains and thereby higher mechanical stress susceptibility. Sequence differences both at DNA and/or amino acid level could alter biochemical or molecular characteristics of starch phosphorylases and in consequence lead to variation in specific gravity of genotypes characterized by a given allelic composition.

Polyphenol oxidases are the major functional candidate genes for the enzymatic browning reaction. Accordingly, markers derived from at least three paralogous $P P O$ genes clustered at the $P P O$ locus on potato chromosome VIII were associated with tuber bruising. The markers POLOXA and POT32PS1- $f$ were highly significantly associated with $\mathrm{SCB}$, which makes them particularly interesting for MAS aiming at increased bruising resistance not compromised by low specific gravity of tubers. The association of the POLOXA marker with increased bruising susceptibility (BI and SCB) is especially intriguing, regarding the reported tissue specific expression of the POTP1 gene that is high in leaf tissue but restricted in tubers [16]. Sequencing the POLOXA amplicon revealed that the corresponding primer pair tags more than one PPO gene or allele (unpublished data). The observed association might therefore result from a $P P O$ gene other than POTP1, which is expressed in tubers. Selection against the rather frequent (35\%) POLOXA marker should improve the average bruising resistance in a breeding population. The single strand conformation polymorphism (SSCP) fragment POT32PS1-f, was derived from the POT32 gene by subjecting the CAPS marker for allele 1 described by Werijet al. [20] to single strand conformation analysis. POT32 allele 1 co-localized with a large effect QTL for enzymatic discoloration on chromosome VIII and its presence increased enzymatic discoloration [20]. The fact that SCB is virtually uncoupled from the structural components of tuber bruising makes it more comparable to enzymatic discoloration catalyzed by PPO. The POT32PS1- $f$ marker decreased SCB and therefore likely represents a novel $P P O$ allele that was detected due to the higher resolution of SSCP analysis and the use of tetraploid breeding material instead of the diploid mapping population employed by Werij et al. [20].

Furthermore, a particularly interesting candidate gene is a putative class III lipase, which has been discovered de novo by comparing the tuber proteome of bruising resistant and susceptible cultivars (Urbany et al., in preparation). SSCP markers derived from this gene showed significant associations with either $\mathrm{BI}, \mathrm{SCB}$ and TS (LIPIII-27-1h) or BI and SG (LIPIII-27-1e) or SG and TY (LIPIII-27-a) (Table 4). The marker LIPIII-27-1h, present in $80 \%$ of the tetraploid individuals, was associated with reduced SCB and a trend towards round shaped tubers. A functional role of lipases in tuber bruising, specific gravity or shape is not obvious, apart from membrane modification by altering lipid composition. Recent work on the closest homolog of potato class III lipases, the CaPLA1 gene encoding a hot pepper phospholipase A1, points to a possible connection with tuber bruising. Seo et al. [55] proposed that CaPLA1 is involved in the regulation of cell shape and number as well as the control of carbon flux through gluconeogenesis and $\beta$-oxidation. In addition, it was postulated that the enzyme is involved in lipid signalling and thereby regulates cellular and biochemical functions in heterotrophic plant tissue. The CaPLA1 homologous potato unigene LIPIII-27 (SGN-U269327) might fulfil analogous functions in heterotrophic tuber tissue, thereby indirectly influencing tuber bruising susceptibility and specific gravity. A putative role in the regulation of cell shape and number could explain why the marker LIPIII-27-1h associates with tuber shape as well.

The remaining candidate markers associated with tuber bruising and specific gravity can be classified as genes involved in polyphenol synthesis $(\mathrm{St} 4 \mathrm{Cl}, \mathrm{Hqt}$, Hct, C3h, C4h), redox homeostasis (Cat, Zep) and general carbohydrate and energy metabolism (PHA1, AGPaseB).

Populations of cultivated, tetraploid potato are characterized by large haplotype blocs, resulting from a limited number of meiotic recombination events separating the individuals and/or selection [56]. This is demonstrated by the finding of highly significant associations with SSR markers that did not encode any candidate gene. Large haplotype blocs are on the one hand favourable for the identification of diagnostic markers for breeding purposes but on the other hand prevent the verification of candidate genes by association genetics. By using linear regression for the identification of significant marker trait association, marker redundancy could be limited. The results concerning bruising validate the main candidate associations for polymorphic fragments derived from starch phosphorylase and 4-coumarate CoA ligase genes as well as the non-coding SSR locus StIO13 previously identified by the mixed model approach (Table 5). PPO markers significantly associated with BI using mixed model statistics were also tagged by linear regression when the probability threshold was increased to $\mathrm{P}<$ 0.005 (data not shown). In the case of SG, markers with a significant impact on this trait by linear regression 
originate either from the $P H O 1 B$ gene or the non coding SSR locus StI013, which also influenced BI. Regarding tuber yield and SCB, linear regression resulted in the repeated selection of significantly associated marker fragments from the L-galactono-1,4-lactone dehydrogenase and hydroxycinnamoyl CoA quinate transferase genes, respectively. These results strongly support the impact of candidate genes identified by both association analysis and linear regression on the analyzed traits. The ambiguity whether a candidate gene variant is causal for the trait effect or whether the association observed is due to LD with the causal gene has to be resolved by further functional analysis of candidate gene alleles. Candidate gene alleles associated with positive or negative trait values can be isolated and functionally characterized in heterologous model systems such as yeast, Arabidopsis or tobacco [38,57-60].

Multiple correlations between traits were evident in the investigated population. Most of these correlations can be explained on a physiological or genetic basis, as described above for tuber bruising susceptibility and specific gravity. Plant maturity was correlated with specific gravity, yield and bruising susceptibility. This might be due to a longer vegetation period (later maturity) that results consequently in higher tuber yield and specific gravity, and indirectly in higher bruising. The reason for the negative correlation between tuber shape and bruising is probably physical. The surface of round shaped tubers is more exposed to mechanical impact than oblong tubers.

The interconnection of the traits investigated and the associated marker fragments identified are a valuable resource for breeders and molecular biologists dealing with enzymatic tissue discoloration and in particular potato tuber bruising. Functional studies will have to provide further evidence on whether and how sequence diversity of candidate genes results in functional differences and thereby explains phenotypic variation. The present work is the result of a collaboration between the breeding industry and basic research and accentuates the efforts to transfer the genetic and molecular knowledge gained during such studies into the field.

\section{Conclusions}

In conclusion, our study demonstrates that association genetics based on candidate genes in advanced breeding populations of potato allows the identification of diagnostic markers that are valuable for MAS, especially for complex traits such as tuber bruising. Twenty one highly significant $(\mathrm{p}<0.001)$ and robust marker-trait associations were identified that will facilitate the diagnosis and combination of superior alleles in breeding programs. For example, selection against the rather frequent POLOXA allele and enrichment of the rare
POT32 allele (POT32PS1-Hpy-f) associated with higher and lower bruising susceptibility, respectively, should improve tuber quality with respect to blackspot bruising.

The associations found with certain candidate genes such as lipase class III point to new structural and biochemical properties that play a role in bruising. The identified candidate genes and their associations with enzymatic discoloration and bruising are a basis to elucidate the underlying molecular networks and the sequence diversity at the given loci, not only in potato but also in other fruits and vegetables that suffer from mechanical damage.

\section{Methods}

\section{Plant material}

A population of 205 tetraploid potato genotypes, representing the variation for bruising susceptibility present in advanced commercial breeding materials, was used in this study. Variety names, sample coding and corresponding breeder or distributor are given in Additional file 1 . The population consisted of a common set of 85 tetraploid varieties and 20 genotypes each from the current breeding programs of six breeding companies: EUROPLANT Pflanzenzucht GmbH (EU); SaKa Pflanzenzucht GbR (SA); NORIKA GmbH (NO); Bavaria-Saat GmbH (BS); Gut Bütow Dr. K. - H. Niehoff (NE); Saatzucht Berding (BE) (Additional file 5). These 120 genotypes did not contain full siblings. Historical pedigree information for most of the varieties is available at http://potatodbase.dpw.wau.nl/potatopedigree[61].

\section{Collection of phenotypic data}

Each breeding company propagated in 2007 and 2008 the common set of 85 potato varieties and the 20 'breeder specific' clones in the field under standard phytosanitary regimes, with two replicates each at six breeding stations in Germany (EU, Kaltenberg; SA, Windeby; NO, Groß-Lüsewitz; BS, Schrobenhausen; NE, Bütow; BE, Petersgroden). Each replicate comprised 10 plants. Tuber bruising was evaluated according to the guideline from the German variety office (Bundessortenamt 30.03.2006). About $25 \mathrm{~kg}$ tubers were stored at $4^{\circ}-6^{\circ} \mathrm{C}$. Bruising tests were performed in duplicate between December (very early and early genotypes) and January (mid early to late genotypes) by exposing 8-12 kg tubers to mechanical impact in a rotating washing machine or other shaking device. The duration of mechanical stress (usually $45-90 \mathrm{sec}$ ) was calibrated against the standard varieties 'Berber', 'Tomensa', 'Laura' and 'Albatros'. The bruised tubers were stored at room temperature in the dark for 4-5 days and then cut into half. Bruising susceptibility was visually scored either as 'no discoloration', 'light discoloration' (L), 'average discoloration' (M) or 'strong discoloration' (S). The bruising index (BI) was 
calculated from the observations according to $\mathrm{BI}=[(0.3 \mathrm{~L}+0.5 \mathrm{M}+\mathrm{S}) /$ total tuber number $] \times 100$, with $L, M$ and $S$ being the fraction of tubers in the $\mathrm{L}, \mathrm{M}$ or $\mathrm{S}$ bruising category, respectively. The bruising index ranged from 0 (resistant to bruising) to 100 (highest bruising susceptibility). Tuber shape (TS), scores ranging from 1 (completely circular) to 9 (longitudinal), and plant maturity (PM), scores ranging from 1 (very early) to 9 (very late) were also evaluated in accordance with the assessments of the German variety office. Tuber starch content (percent fresh weight) was quantified by measuring specific gravity (SG) [62]. Tuber yield (TY) was determined by tuber weight per area planted (dt/ha). The trait 'starch corrected bruising' (SCB) was obtained from the residuals of the regression of the bruising index BI on SG.

\section{Genotyping}

Genomic DNA was isolated from freeze-dried leaf tissue as described [36]. DNA fragments were amplified by PCR (polymerase chain reaction) according to [36] using primers and annealing temperatures specified in Additional file 3 . The extension time was adjusted to amplicon length ranging from $30 \mathrm{~s}$ to $2 \mathrm{~min}$. DNA polymorphisms in the amplicons were detected by SSCP (single strand conformation polymorphism) analysis as described [36], or by agarose gel electrophoresis of amplicons with (CAPS = cleaved amplified polymorphic sequence) or without (DA = direct amplification; SCAR = sequence characterized amplified region) restriction enzyme digestion. Simple sequence repeat (SSR) markers were PCR amplified from genomic DNA of tetraploid, heterozygous individuals using primers and conditions reported in $[39,63,64]$ the SGN database (http://solgenomics.net/) and Additional file 6. SSR alleles were separated on Spreadex gels (Elchrom Scientific, CH-6330 Cham, Switzerland) according to the supplier's instructions. DNA fragments of all marker types were recorded in each individual as 1 for presence, 0 for absence or as missing value in unclear cases.

\section{Phenotypic data analysis}

The fact that each breeding company evaluated their clones together with the common set of 85 varieties was used to perform a joint analysis of all six locations, where each year-location combination was treated as an environment. The phenotypic data were analyzed using the statistical model:

$$
y_{i j k}=\mu+g_{i}+l_{j}+(g l)_{i j}+r_{j k}+e_{i j k}
$$

where $y_{i j k}$ was the entry mean for the $i$ th clone in the $k$ th replication of the $j$ th environment, $\mu$ was an intercept term, $g_{i}$ was the genetic effect of the $i$ th clone, $l_{j}$ was the effect of the $j$ th environment, $(g l)_{i j}$ was the effect of genotype by environment interaction, $r_{j k}$ was the effect of the $k$ th replicate at the $j$ th location, and $e_{i j k}$ was the residual. For estimation of variance components, all effects were considered as random. Heritability on an entry mean basis was calculated as $h^{2}=\frac{\sigma_{g}^{2}}{\sigma_{g}^{2}+\frac{\bar{w}}{2}}$, where $\sigma_{g}^{2}$ was the genetic variance and $\bar{w}$ the mean variance of a difference between two adjusted entry means [65].

For calculation of adjusted entry means, $g_{i}$ was considered as fixed. Over all environments, an adjusted entry mean $M_{i}$ was calculated for each of the 205 clones as: $M_{i}=\hat{\mu}+\hat{g}_{i}$, where $\hat{\mu}$ and $\hat{g}_{i}$ denote the generalized least square estimates of $\mu$ and $g_{i}$, respectively.

\section{Population structure and association analysis}

Associations among the 205 tetraploid potato clones were revealed with principal coordinate analysis based on the allele frequency matrix. This analysis was performed based on 157 SSR marker alleles using the statistical software $\mathrm{R}$ [66].

The PK method described by [67] was used for detection of marker-phenotype associations:

$$
M_{i p}=\mu+\sum P_{i u} v_{u}+a_{p}+\breve{g}_{i}+e_{i p}
$$

where $M_{i j p}$ is the adjusted entry mean of the $i$ th potato clone carrying the $p$ th allele, $\mu$ an intercept term, $v_{u}$ the effect of the $u$ th column of the population structure matrix P, $a_{p}$ the effect of allele $p, \breve{g}_{i}$ the genetic effect of the $i$ th entry except for $a_{p}, e_{i p}$ the residual.

Following Stich and Melchinger[68], the first $q$ principal components of an allele frequency matrix were used as $\mathrm{P}$ matrix. $q$ was chosen in such a way that the explained variance of the first $q$ principal components was about $25 \%$.

The variance of the random effects $\breve{g}=\left\{\breve{g}_{1}, \ldots, \breve{g}_{205}\right\}$ and $e=\left\{e_{1}, 1, \ldots, e_{205}, \mathrm{p}\right\}$ was assumed to be $\operatorname{Var}(\breve{g})=2 \mathrm{~K} \sigma_{\breve{g}}^{2}$ and $\operatorname{Var}(e)=\mathrm{R} \sigma_{r}^{2}$. K was a $205 \times 205$ matrix of kinship coefficients that define the degree of genetic covariance between all pairs of entries and was calculated using SPAGEDI [69]. R was a $205 \times 205$ matrix in which the off-diagonal elements were 0 and the diagonal elements were calculated as the square of the standard errors of the adjusted entry means. $\sigma_{\overline{8}}^{2}$ was the genetic variance and $\sigma_{r}^{2}$ was the residual variance, both estimated by REML.

In order to take into account the LD between markers, we used in addition to a single marker approach a 
multiple forward regression approach to identify based on the above described PK model those marker combinations, which explain best the genotypic variation. A P-to-enter criterion of 0.001 was used.

All mixed-model calculations were performed with ASReml release 2.0 [70].

\section{Additional material}

\begin{abstract}
Additional file 1: Genotype and sample identification with the corresponding breeder/distributor affiliation.

Additional file 2: Marker trait associations in the ALL population $(P<0.01)$.

Additional file 3: Locus and marker information

Additional file 4: Electrophoresis band distribution and

identification of significant markers at $\mathbf{P}<\mathbf{0 . 0 0 1}$. In the case of SSR and DALP markers gel pictures show the band pattern and distribution of the corresponding marker fragments. Polymorphic bands are labelled as described in Additional table 3 and listed with their respective size in basepairs. SSRs were analyzed according to the procedures given in the methods section. DALP markers were separated on agarose gels. SSCP analysis was carried out as described elsewhere [36] Exemplary panes show fragment distribution and labelling. Allele ID is according to Additional table 3. The size of polymorphic SSCP fragments was not determined. Legend - (A) StI013; (B) StI024; (C) SSR327; (D) POLOXA; (E) PHO1A; (F) PHO1B-1; (G) LIPIII-27-1; (H) POT32PS1-Hpy; (I) 4CL-1; (J); 4CL-2; (K) HQT; (L); GLDH. Significant marker-trait associations are indicated by the specific trait abbreviation: bruising susceptibility (BI), specific gravity (SG), starch corrected bruising (SCB), and tuber yield (TY).
\end{abstract}

Additional file 5: Experimental design of the field experiments and data evaluation. Breeders are listed with their corresponding abbreviation. They cultivated and evaluated the common set of 85 potato varieties in two consecutive years (2007/2008) for bruising susceptibility (BI), specific gravity (SG), tuber shape (TS), tuber yield (TY), starch corrected bruising (SCB) and plant maturity (PM). In addition each breeder evaluated 20 own breeding clones, selected based on a specific gravity below 20 percent, a balanced tuber shape, no extreme maturity phenotype, not being closely related, and one half each having a high or a low bruising phenotype.

Additional file 6: SSR marker information

\section{Acknowledgements}

Part of the work was carried out in the Department for Genetics and Plant Breeding headed by Maarten Koornneef. The research was funded by grants from the German Federal Ministry for Economy and Technology under the program 'promotion of innovative networks' (InnoNet 16IN0417) with VDIVDE as project executing institution.

\section{Author details \\ ${ }^{1}$ Max Planck Institute for Plant Breeding Research, 50829 Cologne; Germany. ${ }^{2}$ Bavaria Saat BGB GmbH, 86529 Schrobenhausen; Germany. ${ }^{3}$ Saatzucht Berding, 26345 Bockhorn-Petersgroden; Germany. ${ }^{4}$ NORIKA, 18190 Groß Lüsewitz; Germany. ${ }^{5}$ Dr. K.-H. Niehoff, Gut Bütow, 17209 Bütow; Germany. ${ }^{6}$ Böhm-Nordkartoffel Agrarproduktion OHG, 84085 Langquaid; Germany. ${ }^{7}$ BIOPLANT GmbH, 29547 Ebstorf; Germany. ${ }^{8}$ Böhm-Nordkartoffel Agrarproduktion GbR, 29574 Ebstorf; Germany. ' Saka-Pflanzenzucht G.b.R., 24340 Windeby; Germany.}

\section{Authors' contributions}

CU and LS carried out the molecular genetics studies and the laboratory procedures. CG and CU conceived of the study, designed and evaluated the experiments and drafted the manuscript. BS carried out the statistical analysis and contributed to draft the manuscript. KHN, AB, ET, LUS, HRH, HB, $\mathrm{HJ}, J \mathrm{~L}$ and $J S$ conceived of the study, provided the genetic material, carried out the phenotypic evaluations and coordinated field experiments. All authors read and approved the manuscript.

Received: 22 September 2010 Accepted: 5 January 2011

Published: 5 January 2011

\section{References}

1. Adams JB, Brown HM: Discoloration in Raw and Processed Fruits and Vegetables. Critical Reviews in Food Science and Nutrition 2007, 47(3):319-333.

2. Esquerre C, Gowen AA, O'Donnell CP, Downey G: Initial Studies on the Quantitation of Bruise Damage and Freshness in Mushrooms Using Visible-Near-Infrared Spectroscopy. J Agric Food Chem 2009, 57:1903-1907.

3. Friedman M: Nutritional consequences of food processing. Forum Nutr 2003, 56:350-352.

4. Matheis G: Enzymatic browning of foods. Zeitschrift für Lebensmitteluntersuchung und -Forschung A 1983, 176(6):454-462.

5. Prieto H, Utz D, Castro A, Aguirre C, Gonzalez-Aguero M, Valdes H, Cifuentes N, Defilippi BG, Zamora P, Zuniga G, et al: Browning in Annona cherimola fruit: role of polyphenol oxidase and characterization of a coding sequence of the enzyme. J Agric Food Chem 2007, 55(22):9208-9218.

6. Ravi V, Aked J: Review on tropical root and tuber crops. II. Physiological disorders in freshly stored roots and tubers. Crit Rev Food Sci Nutr 1996, 36(7):711-731.

7. Schmitz GE, Sullivan ML, Hatfield RD: Three polyphenol oxidases from red clover (Trifolium pratense) differ in enzymatic activities and activation properties. J Agric Food Chem 2008, 56(1):272-280.

8. Segovia-Bravo KA, Jaren-Galan M, Garcia-Garcia P, Garrido-Fernandez A: Characterization of polyphenol oxidase from the Manzanilla cultivar (Olea europaea pomiformis) and prevention of browning reactions in bruised olive fruits. J Agric Food Chem 2007, 55(16):6515-6520.

9. McGarry A, Hole CC, Drew RLK, Parsons N: Internal damage in potato tubers: a critical review. Postharvest Biology and Technology 1996, 8:239-258.

10. Friedman M: Chemistry, Biochemistry, and Dietary Role of Potato Polyphenols. A Review. Journal of Agricultural and Food Chemistry 1997, 45(5):1523-1540

11. Vaughn KC, Lax AR, Duke SO: Polyphenol oxidase: The chloroplast oxidase with no established function. Physiologia Plantarum 1988, 72(3):659-665.

12. Spagna G, Barbagallo RN, Chisari M, Branca F: Characterization of a tomato polyphenol oxidase and its role in browning and lycopene content. $J$ Agric Food Chem 2005, 53(6):2032-2038.

13. Cantos E, Tudela JA, Gil Ml, Espin JC: Phenolic compounds and related enzymes are not rate-limiting in browning development of fresh-cut potatoes. J Agric Food Chem 2002, 50(10):3015-3023.

14. Fenoll LG, Rodriguez-Lopez JN, Varon R, Garcia-Ruiz PA, Garcia-Canovas F, Tudela J: Kinetic characterisation of the reaction mechanism of mushroom tyrosinase on tyramine/dopamine and L-tyrosine methyl esther/L-dopa methyl esther. Int J Biochem Cell Biol 2002, 34(12):1594-1607.

15. Hunt MD, Eannetta NT, Yu H, Newman SM, Steffens JC: cDNA cloning and expression of potato polyphenol oxidase. Plant Mol Biol 1993, 21(1):59-68.

16. Thygesen PW, Dry IB, Robinson SP: Polyphenol oxidase in potato. A multigene family that exhibits differential expression patterns. Plant Physiol 1995, 109(2):525-531.

17. Bachem CWB, Speckmann G-J, van der Linde PCG, Verheggen FTM, Hunt MD, Steffens JC, Zabeau M: Antisense Expression of Polyphenol Oxidase Genes Inhibits Enzymatic Browning in Potato Tubers. Nat Biotech 1994, 12(11):1101-1105.

18. Coetzer C, Corsini D, Love S, Pavek J, Tumer N: Control of enzymatic browning in potato (Solanum tuberosum L.) by sense and antisense RNA from tomato polyphenol oxidase. J Agric Food Chem 2001, 49(2):652-657.

19. Rommens CM, Ye J, Richael C, Swords K: Improving potato storage and processing characteristics through all-native DNA transformation. J Agric Food Chem 2006, 54(26):9882-9887.

20. Werij JS, Kloosterman B, Celis-Gamboa C, de Vos CH, America T, Visser RG, Bachem CW: Unravelling enzymatic discoloration in potato through a combined approach of candidate genes, QTL, and expression analysis. Theor Appl Genet 2007, 115(2):245-252. 
21. Corsini D, Pavek J, Dean B: Differences in free and protein-bound tyrosine among potato genotypes and the relationship to internal blackspot resistance. American Journal of Potato Research 1992, 69(7):423-435.

22. Mondy NI, Munshi CB: Effect of maturity and storage on ascorbic acid and tyrosine concentrations and enzymic discoloration of potatoes. Journal of Agricultural and Food Chemistry 1993, 41(11):1868-1871.

23. el-Shimi NM: Control of enzymatic browning in apple slices by using ascorbic acid under different conditions. Plant Foods Hum Nutr 1993, 43(1):71-76.

24. Henze RE: Inhibition of enzymatic browning of chlorogenic acid solutions with cysteine and glutathione. Science 1956 123(3209):1174-1175.

25. Stevens LH, Davelaar E: Biochemical Potential of Potato Tubers To Synthesize Blackspot Pigments in Relation to Their Actual Blackspot Susceptibility. Journal of Agricultural and Food Chemistry 1997, 45(11):4221-4226.

26. de Pater $S$, Caspers M, Kottenhagen M, Meima H, ter Stege R, Vetten N: Manipulation of starch granule size distribution in potato tubers by modulation of plastid division. Plant Biotechnology Journal 2006, 4(1):123-134.

27. Riewe D, Grosman L, Fernie AR, Wucke C, Geigenberger P: The Potato-Specific Apyrase Is Apoplastically Localized and Has Influence on Gene Expression, Growth, and Development. Plant Physiol 2008, 147(3):1092-1109.

28. Verma S, Sharma T, Joshi K: Relation between specific gravity, starch and nitrogen content of potato tubers. Potato Research 1975, 18(1):120-122.

29. Smith AM, Denyer K, Martin C: The synthesis of the starch granule. Annual Review of Plant Physiology and Plant Molecular Biology 1997, 48(1):67-87.

30. Osborn TC, Alexander DC, Fobes JF: Identification of restriction fragment length polymorphisms linked to genes controlling soluble solids content in tomato fruit. TAG Theoretical and Applied Genetics 1987, 73(3):350-356.

31. Salvi S, Tuberosa R: To clone or not to clone plant QTLs: present and future challenges. Trends Plant Sci 2005, 10(6):297-304.

32. Luo ZW, Hackett CA, Bradshaw JE, McNicol JW, Milbourne D: Construction of a genetic linkage map in tetraploid species using molecular markers. Genetics 2001, 157(3):1369-1385.

33. Pflieger S, Lefebvre V, Causse M: The candidate gene approach in plant genetics: a review. Molecular Breeding 2001, 7(4):275-291.

34. Love SL: Founding clones, major contributing ancestors, and exotic progenitors of prominent north american potato cultivars. Amer $J$ of Potato Res 1999, 76:263-272.

35. Li L, Paulo MJ, Strahwald J, Lubeck J, Hofferbert HR, Tacke E, Junghans H, Wunder J, Draffehn A, van Eeuwijk F, et al: Natural DNA variation at candidate loci is associated with potato chip color, tuber starch content, yield and starch yield. Theor App/ Genet 2008, 116:1167-1181.

36. Li L, Strahwald J, Hofferbert HR, Lubeck J, Tacke E, Junghans H, Wunder J, Gebhardt C: DNA variation at the invertase locus invGE/GF is associated with tuber quality traits in populations of potato breeding clones. Genetics 2005, 170(2):813-821.

37. Gonzalez-Martinez SC, Wheeler NC, Ersoz E, Nelson CD, Neale DB: Association genetics in Pinus taeda L. I. Wood property traits. Genetics 2007, 175(1):399-409.

38. Pajerowska-Mukhtar K, Stich B, Achenbach U, Ballvora A, Lübeck J, Strahwald J, Tacke E, Hofferbert H-R, llarionova E, Bellin D, et al: Single nucleotide polymorphisms in the Allene Oxide Synthase 2 gene are associated with field resistance to late blight in populations of tetraploid potato cultivars. Genetics 2009, 181(3):1115-1127.

39. Odeny DA, Stich B, Gebhardt C: Physical organization of mixed protease inhibitor gene clusters, coordinated expression and association with resistance to late blight at the StKI locus on potato chromosome III. Plant Cell Environ 2010, 33:2149-2161.

40. Breseghello F, Sorrells ME: Association mapping of kernel size and milling quality in wheat (Triticum aestivum L.) cultivars. Genetics 2006, 172:1165-1177.

41. D'hoop BB, Paulo MJ, Mank RA, van Eck HJ, van Eeuwijk FA: Association mapping of quality traits in potato (Solanum tuberosum L.). Euphytica 2008, 161:47-60.

42. Eckert A, Bower AD, Wegrzyn JL, Pande B, Jermstad KD, Krutovsky KV, St Clair JB, Neale DB: Association Genetics of Coastal Douglas-fir (Pseudotsuga menziesii var. menziesii, Pinaceae) I. Cold-hardiness Related Traits. Genetics 2009, genetics.109.102350.
43. Mackay I, Powell W: Methods for linkage disequilibrium mapping in crops. Trends in Plant Science 2007, 12(2):57-63.

44. Nordborg N, Hu TT, Ishino Y, Jhaveri J, Toomajian C, Zheng H, Bakker E, Calabrese P, Gladstone J, Goyal R, et al: The pattern of polymorphism in Arabidopsis thaliana. PLoS Biology 2005, 3:e196.

45. Weir BS: Linkage Disequilibrium and Association Mapping. Annual Review of Genomics and Human Genetics 2008, 9(1):129-142.

46. Fisher $P$, Noyes $H$, Kemp $S$, Stevens R, Brass A: A systematic strategy for the discovery of candidate genes responsible for phenotypic variation. Methods Mol Biol 2009, 573:329-345.

47. Linghu B, Snitkin ES, Hu Z, Xia Y, Delisi C: Genome-wide prioritization of disease genes and identification of disease-disease associations from an integrated human functional linkage network. Genome Biol 2009, 10(9): R91.

48. Li B, Leal SM: Discovery of rare variants via sequencing: implications for the design of complex trait association studies. PLoS Genet 2009, 5(5): e1000481.

49. Thornsberry JM, Goodman MM, Doebley J, Kresovich S, Nielsen D, Buckler ES: Dwarf8 polymorphisms associate with variation in flowering time. Nat Genet 2001, 28:286-289.

50. Belo A, Zheng P, Luck S, Shen B, Meyer DJ, Li B, Tingey S, Rafalski A: Whole genome scan detects an allelic variant of fad2 associated with increased oleic acid levels in maize. Mol Genet Genomics 2008, 279(1):1-10.

51. Escribano J, Gandia-Herrero F, Caballero N, Pedreno MA: Subcellular localization and isoenzyme pattern of peroxidase and polyphenol oxidase in beet root (Beta vulgaris L.). J Agric Food Chem 2002, 50(21):6123-6129.

52. Partington JC, Smith C, Bolwell GP: Changes in the location of polyphenol oxidase in potato (Solanum tuberosum L.) tuber during cell death in response to impact injury: comparison with wound tissue. Planta 1999, 207(3):449-460.

53. Partington JC, Bolwell GP: Purification of polyphenol oxidase free of the storage protein patatin from potato tuber. Phytochemistry 1996, 42(6):1499-1502.

54. Albrecht T, Koch A, Lode A, Greve B, Schneider-Mergener J, Steup A: Plastidic (Pho1-type) phosphorylase isoforms in potato (Solanum tuberosum) plants: expression analysis and immunochemical characterization. Planta 2001, 213:602-613.

55. Seo YS, Kim EY, Mang HG, Kim WT: Heterologous expression, and biochemical and cellular characterization of CaPLA1 encoding a hot pepper phospholipase A1 homolog. Plant J 2008, 53(6):895-908.

56. Simko I, Haynes KG, Jones RW: Assessment of linkage disequilibrium in potato genome with single nucleotide polymorphism markers. Genetics 2006, 173(4):2237-2245.

57. Fridman E, Carrari F, Liu Y-S, Fernie AR, Zamir D: Zooming in on a quantitative trait for tomato yield using interspecific introgressions. Science 2004, 305(5691):1786-1789.

58. Maron LG, Pineros MA, Guimaraes CT, Magalhaes JV, Pleiman JK, Mao C, Shaff J, Belicuas SN, Kochian LV: Two functionally distinct members of the MATE (multi-drug and toxic compound extrusion) family of transporters potentially underlie two major aluminum tolerance QTLs in maize. Plant J 2009, 61:728-740.

59. Ren Z, Zheng Z, Chinnusamy V, Zhu J, Cui X, lida K, Zhu JK: RAS1, a quantitative trait locus for salt tolerance and $A B A$ sensitivity in Arabidopsis. Proc Natl Acad Sci USA 2010, 107(12):5669-5674.

60. Orsi $\mathrm{CH}$, Tanksley SD: Natural variation in an ABC transporter gene associated with seed size evolution in tomato species. PLoS Genet 2009 5(1):e1000347.

61. van Berloo R, Hutten RCB: Peditree: Pedigree Database Analysis and Visualization for Breeding and Science. J Hered 2005, 96(4):465-468.

62. Scheele CV, Svensson G, Rasmussen J: Die Bestimmung des Stärkegehaltes und der Trockensubstanz der Kartoffel mit Hilfe des spezifischen Gewichts. Landw VersStn 1937, 127:67-96.

63. Milbourne D, Meyer RC, Collins AJ, Ramsay LD, Gebhardt C, Waugh R: Isolation, characterisation and mapping of simple sequence repeat loci in potato. Mol Gen Genet 1998, 259(3):233-245.

64. Feingold S, Lloyd J, Norero N, Bonierbale M, Lorenzen J: Mapping and characterization of new EST-derived microsatellites for potato (Solanum tuberosum L.). Theor App/ Genet 2005, 111(3):456-466. 
65. Holland JB, Nyquist WE, Cervantes-Martinez CT: Estimating and interpreting heritability for plant breeding: An update. Plant Breed Rev 2003, 22:9-113.

66. R Development Core Team: R: A language and environment for statistical computing. Vienna, Austria; 2004

67. Yu J, Pressoir G, Briggs WH, Vroh Bi I, Yamasaki M, Doebley JF, McMullen MD, Gaut BS, Nielsen DM, Holland JB, et al: A unified mixedmodel method for association mapping that accounts for multiple levels of relatedness. Nat Genet 2006, 38(2):203-208.

68. Stich B, Melchinger AE: Comparison of mixed-model approaches for association mapping in rapeseed, potato, sugar beet, maize, and Arabidopsis. BMC Genomics 2009, 10:94

69. Hardy OJ, Vekemans X: SPAGEDi: a versatile computer program to analyse spatial genetic structure at the individual or population levels. Mol Ecol Notes 2002, 2(4):618-620.

70. Gilmour AR, Gogel BJ, Cullis BR, Thompson R: ASReml user guide release 2.0. VSN International Ltd; 2006.

doi:10.1186/1471-2164-12-7

Cite this article as: Urbany et al: Association genetics in Solanum tuberosum provides new insights into potato tuber bruising and enzymatic tissue discoloration. BMC Genomics 2011 12:7.

\section{Submit your next manuscript to BioMed Central} and take full advantage of:

- Convenient online submission

- Thorough peer review

- No space constraints or color figure charges

- Immediate publication on acceptance

- Inclusion in PubMed, CAS, Scopus and Google Scholar

- Research which is freely available for redistribution

Submit your manuscript at www.biomedcentral.com/submit
C Biomed Central 